\title{
Folic-acid metabolism and DNA-repair phenotypes differ between neuroendocrine lung tumors and associate with aggressive subtypes, therapy resistance and outcome
}

\author{
Robert Fred Henry Walter ${ }^{1,2, *}$, Fabian Dominik Mairinger ${ }^{2,3, *}$, Robert Werner ${ }^{4}$, \\ Claudia Vollbrecht ${ }^{3}$, Thomas Hager ${ }^{2}$, Kurt Werner Schmid ${ }^{2}$, Jeremias \\ Wohlschlaeger ${ }^{2,5}$, Daniel Christian Christoph ${ }^{6}$ \\ ${ }^{1}$ Ruhrlandklinik Essen, West German Lung Centre, University Hospital Essen, University of Duisburg-Essen, Essen, Germany \\ ${ }^{2}$ Institute of Pathology, University Hospital Essen, University of Duisburg-Essen, Essen, Germany \\ ${ }^{3}$ Institute of Pathology, Division of Molecular Pathology, Charité, Berlin, Essen, Germany \\ ${ }^{4}$ Department of Pathology, Helios Klinikum Emil von Behring, Berlin, Germany \\ ${ }^{5}$ Institute of Pathology, Ev.-Luth. Diakonissenkrankenhaus Flensburg, Flensburg, Germany \\ ${ }^{6}$ Department of Medical Oncology, West German Cancer Centre, University Hospital Essen, University of Duisburg-Essen, \\ Essen, Germany \\ *These authors have contributed equally to this work \\ Correspondence to: Robert Fred Henry Walter, e-mail: robert.walter@ruhrlandklinik.uk-essen.de \\ Keywords: lung cancer, neuroendocrine pulmonary tumors, folic acid metabolism, DNA repair, NanoString nCounter \\ Received: January 29, 2016 \\ Accepted: January 30, 2016 \\ Published: February 26, 2016
}

\section{ABSTRACT}

Purpose: 25\% of all lung cancer cases are neuroendocrine (NELC) including typical (TC) and atypical carcinoid (AC), large-cell neuroendocrine (LCNEC) and small cell lung cancer (SCLC). Prognostic and predictive biomarkers are lacking.

Experimental Design: Sixty patients were used for nCounter mRNA expression analysis of the folic-acid metabolism (ATIC, DHFR, FOLR1, FPGS, GART, GGT1, SLC19A1, TYMS) and DNA-repair (ERCC1, MLH1, MSH2, MSH6, XRCC1). Phenotypic classification classified tumors (either below or above the median expression level) with respect to the folic acid metabolism or DNA repair.

Results: Expression of FOLR1, FPGS, MLH1 and TYMS (each $\mathrm{p}<0.0001$ ) differed significantly between all four tumor types. FOLR1 and FPGS associated with tumor differentiation (both $\mathrm{p}<0.0001$ ), spread to regional lymph nodes (FOLR1 $\mathrm{p}=0.0001$ and FPGS $\mathrm{p}=0.0038$ ), OS and PFS (FOLR1 $\mathrm{p}<0.0050$ for both and FPGS $\mathrm{p}<0.0004$ for OS).

Phenotypic sorting revealed the Ft-phenotype to be the most prominent expression profile in carcinoids, whereas SCLC presented nearly univocal with the fT and LCNEC with $\mathrm{fT}$ or $\mathrm{ft}$. These results were significant for tumor subtype $(\mathrm{p}<0.0001)$.

Conclusions: The assessed biomarkers and phenotypes allow for risk stratification (OS, PFS), diagnostic classification and enhance the biological understanding of the different subtypes of neuroendocrine tumors revealing potential new therapy options and clarifying known resistance mechanisms.

\section{INTRODUCTION}

Lung cancer is still the leading cause of cancer deaths worldwide with a poor five-year survival of approximately $15 \%$ [1]. Twenty-five percent of all lung tumors belong to the group of neuroendocrine tumors [2] including typical carcinoid (TC) and atypical carcinoid (AC), large-cell neuroendocrine cancer (LCNEC), and small-cell lung cancer (SCLC). Pattern of metastasis and survival rates differ significantly between these subtypes [3, 4].

According to the World Health Organization (WHO) classification from 2004, LCNEC is considered as a type 
of non-SCLC [5]. However, it shares clinical features with SCLC such as a five-year survival of $15 \%$ up to $57 \%$ depending on the reporting source $[2,3]$. Even when diagnosed at an early stage, LCNEC and SCLC show the poorest clinical outcome compared to other malignant lung tumors due to the aggressiveness of these cancer types, but the molecular characteristics of these tumors still remain largely unknown [6]. They occur almost exclusively in patients with a history of smoking and grow very rapidly, whereas lung carcinoids occur frequently in never smokers and younger patients $[4,7-9]$.

A platinum-based combination chemotherapy is currently the standard first-line therapy for patients with advanced Epidermal Growth Factor Receptor $(E G F R)$ gene and Anaplastic Lymphoma Kinase $(A L K)$ gene wild-type non-small cell lung cancer (NSCLC) [10]. The multitarget antifolate pemetrexed is used in combination with cisplatin [11] or carboplatin [12] in non-squamous NSCLC (including metastatic atypical carcinoids and LCNEC) [13] and is often also administered after platinum-based chemotherapy as continuous maintenance therapy, as single agent after progression of first-line therapy $[14,15]$ or given as first-line therapy to patients who are medically unfit for platinum-based combination chemotherapy [16]. Three transporters are identified for the transport of antifolates into eukaryotic cells: the solute carrier family 19, member 1 (SLC19A1, also known as reduced folate carrier), the solute carrier family 46, member 1 (SLC46A1, also known as proto-coupled folate transporter), and the folate receptors of which folate receptor 1 (FOLR1) being the most widely studied isoform [17]. Pemetrexed inhibits folate-dependent enzymes such as thymidylate synthetase (TYMS), dihydrofolate reductase (DHFR) and glycinamide ribonucleotide formyltransferases (GART) [18]. Once pemetrexed is taken up by cells, it undergoes ATP-dependent polyglutamylation catalysed by folylpolyglutamate synthase (FPGS), regulated by the reverse mechanism through gamma-glutamyltransferase 1 (GGT1). Polyglutamylation results in more negatively charged molecules leading to higher intracellular concentration of pemetrexed [19]. Furthermore, pemetrexed shows a more than 60 -fold higher activity when polyglutamylated than in its unmodified form [20]. Many of the enzymes mentioned above are involved in primary and acquired resistance mechanisms against pemetrexed [21].

Mechanism of platinum cytotoxicity includes the formation of bulky DNA adducts (generation of a chemically altered base in DNA by covalent binding of platinum [22, 23] leading to both inter- and intrastrand cross-link accumulation in DNA [23, 24]. Finally, platinum-compounds prevent normal cell replication and trigger apoptosis [25] unless adducts from genomic DNA are repaired [24].

Possible ways in which cancer cells develop a platinum-resistance include an efficient DNA-repair mechanism. The processing of cross-links in mammalian cells is not clearly understood. However, it is known that their processing may involve components belonging to different DNA repair pathways, including the nucleotide excision repair (NER) and the mismatch repair (MMR) pathway [26]. NER is capable of removing numerous types of DNA helix-distorting lesions induced by platinum [27]. The structure specific endonuclease excision repair crosscomplementation group 1 (ERCC1) performs an essential late step in the NER process [27] and is the rate-limiting member of the NER pathway $[23,24]$. Homologous to ERCC1 in NER, X-ray repair complementing 1 (XRCC1) is the key member of the base-excision repair (BER) pathway $[28,29]$. In contrast, MMR is one of the major DNA-repair pathways, which is responsible for the repair of single-base or nucleotide mismatches and insertiondeletion loops.

MutS homologue 2 (MSH2) protein belongs to the MMR pathway and binds to platinum-induced DNA interstrand cross-links recognized by the MutS $\alpha$ complex, a MSH2/MSH6 heterodimer [30, 31], thereby initiating their excision and repair [26]. Additionally, during the recombinational repair processing of interstrand crosslinks, MSH2 cooperates with several components of DNA damage repair pathways, including ERCC1 [26]. MutL homologue 1 (MLH1) protein is also a key component in the MMR pathway being involved in mismatch strand excision and subsequent repair. In malignant pleural mesothelioma, expression levels of enzymes involved in NER and MMR pathways were correlated to each other [32].

Defects in DNA-MMR have been shown to be a mechanism of resistance to cisplatin both in vivo and in vitro [23]. Furthermore, reduced expression levels of MLH1 or MSH2 at the protein and transcriptional level have been reported in some thoracic cancers including lung cancer [26, 33, 34], but for neuroendocrine lung tumors a lack of prognostic and predictive biomarkers associated with response or outcome following chemotherapy limits the improvement of current systemic therapies. A significant amount of these tumors shows a primary or acquired resistance to platinum or antifolate containing therapeutic regimes.

The main aims of our study were to find markers supporting the procedure of pathological diagnosis making in histologically difficult cases and distinguishing rare carcinoids (TC and AC) with metastatic spread, which need systemic treatment, from the less aggressive ones. Furthermore, we aimed at the analyses of prognostic and predictive markers for aggressive subtypes of NELC. Within this group of tumors (e.g. LCNEC) it is of clinical importance to find markers for the correct interpretation of the biological aggressiveness to adapt treatment approaches. Finally, we wanted to characterize the putative resistance mechanisms against platinum or antifolate containing therapeutic regimes using the 
NanoString nCounter system. The nCounter technology is a hybridization-based digital detection method that can be used to analyze mRNA, miRNA and copy number variations (CNV) [35-37]. Two sequence-specific probes were used to detect the target nucleic acid covering approximately $100 \mathrm{nt}$ of the gene of interest. $100 \mathrm{nt}$ were identified as reproducibly detectable/amplifiable length for FFPE-derived nucleic acids [38, 39].

\section{RESULTS}

\section{Study population}

The mean age at date of diagnosis was 58.6 years (median age: 59 years; range 19.5-84.1). Twentyfive patients were male gender $(42 \%)$ and 27 were female $(45 \%)$. For eight patients the gender remained inconclusive. Data about histology, TNM stages and differentiation of the tumors are summarized in Supplementary Table 1. Due to the complete anonymization of all patients after merging with clinical data, lacking data could not be added. An overview of the investigated targets and pathways is summarized in Figure 1. Figure 1A delineates the investigated DNA-repair members and Figure $1 \mathrm{~B}$ the folic acid pathway.

\section{Folic acid metabolism}

With respect to folic acid metabolism, carcinoids showed significantly higher expression than carcinomas for FOLR1 $(\mathrm{p}<0.0001)$, FPGS $(\mathrm{p}<0.0001)$ and GGT1 $(\mathrm{p}=0.0289)$. The opposite was found for TYMS $(\mathrm{p}<0.0001)$. These results are summarized in Figure 2A-2D. In line with that, FOLR1 ( $<<0.0001), F P G S(\mathrm{p}<0.0001), G G T 1$ $(\mathrm{p}=0.0366)$ and TYMS $(\mathrm{p}<0.0001)$ associated with grade of differentiation as shown in Supplementary Figure S1A-S1D. Furthermore, decreasing FOLR1 and FPGS expression associated significantly with increasing malignancy of the investigated NELC with respect to TNM classification (TNM stage: FOLR1 p=0.0049, spread to regional lymph nodes: FOLR $1 \mathrm{p}=0.0001$, FPGS $\mathrm{p}=0.0038$ ). The results are depicted in Supplementary Figure S2A-S2C. Both showed significantly higher expression in female patients $(F O L R 1 \mathrm{p}=0.0037$, FPGS $\mathrm{p}=0.0489$ ) (data not shown).

Besides, further significant correlations for members of the folic acid pathway were found for TNM criteria and are summarized in Table 1.

After identification of FOLR1 and FPGS as markers for more aggressive NELC, further correlations between folic acid pathway members were investigated. A ratio between FOLR1 and SLC19A1 was calculated to identify the prominent uptake mechanism for each tumor subtype. The ratio correlated significantly with tumor type $(\mathrm{p}<0.0001$, Figure $3 \mathrm{~A})$ and identified FOLR1 to mediate the uptake in TC to LCNEC with an inverted ratio in SCLC, where SLC19A1 seems to mediate the folic acid uptake. Next, the correlation between uptake (FOLR1), activation (FPGS) and utilization (TYMS) was investigated by calculating a ratio between FOLR1 and TYMS as well as FPGS and TYMS. These ratios were calculated to determine the cellular throughput of the folic acid metabolism and associated significantly with tumor type (both $\mathrm{p}<0.0001$, Figure 3B-3C). A misbalance was seen between carcinoids and carcinomas. In contrast to carcinoids, carcinomas seem to have faster utilization via TYMS than their uptake can provide. The ratio between activation of folic acid via FPGS and inactivation via $G G T 1$ was also tested, but reached no statistical significance (data not shown).

Furthermore, a phenotypic pathway sorting was performed. The rationale to test for certain phenotypes was their ability to differentiate the distinct tumor types by system biological means. The samples were classified as either having mRNA expression counts above the median (depicted by capital letters e.g. F or T) or below median (depicted by lowercase letters e.g. $f$ or $t$ ). Figure 4A-4B depicts the folic acid phenotypes for A) FOLR1 (median=313 counts) and TYMS (median=341 counts) and B) FPGS (median=665 counts) and TYMS. With respect to these phenotypes, SCLC showed one predominant pattern (fT), indicating lower folic acid uptake and activation compared to their turnover rate. In contrast, $\mathrm{AC}$ and $\mathrm{TC}$ predominantly associated with the Ft-phenotype having high uptake and activation but a considerably low utilization of folic acid. LCNEC were more heterogenic, but two-third of all LCNEC cases associated with $\mathrm{ft}$ - or fT-phenotype indicating a low uptake and activation rate.

FOLR1 $(\mathrm{p}=0.0014, \mathrm{HR}=1)$ and FPGS $(\mathrm{p}<0.0004$, $\mathrm{HR}=1$ ) associated significantly with $\mathrm{OS}$, but due to a hazard ratio of one they have negligible clinical relevance (shown in Figure 5A-5B). Additionally, the ratios of FOLR1 and SLC19A1 ( $\mathrm{p}=0.0017, \mathrm{HR}=1.05), F O L R 1$ and TYMS $(\mathrm{p}<0.0040, \mathrm{HR}=1)$ as well as FPGS and TYMS $(\mathrm{p}<0.0001, \mathrm{HR}=2.54$, Figure $5 \mathrm{C}$ ) associated with overall survival (further data not shown due to repetitiveness to Figure 5A-5C).

For PFS, FOLR1 $(\mathrm{p}=0.0049, \mathrm{HR}=1)$, FOLR1 and TYMS ratio $(\mathrm{p}=0.0200, \mathrm{HR}=0.26), F O L R 1$ and $S L C 19 A 1$ ratio $(\mathrm{p}=0.0223, \mathrm{HR}=0.69)$ as well as $F P G S$ and TYMS ratio $(\mathrm{p}=0.0225, \mathrm{HR}<0.01)$ reached statistical significance (data not shown due to repetitiveness to Figure 5A-5C).

Assessment of the supposed ratios showed a high merit with clinically relevant hazard ratios compared to single marker evaluation. Especially, the FPGS/TYMS ratio presented with a high discriminative power between poor and good prognosis and response to therapy.

The supposed phenotypes were not correlated with survival data due to the low number of cases per phenotype. 


\section{DNA-repair members}

Members of the DNA-repair pathway correlated significantly with tumor type (ERCC1 $\mathrm{p}=0.0021, \mathrm{MLH1}$ $\mathrm{p}<0.0001$, XRCC1 $\mathrm{p}=0.0131$, MSH6 $\mathrm{p}=0.0064)$ (data not shown) as well as an MLH1/MSH2 ratio ( $\mathrm{p}<0.0010)$, which was calculated as stated above (depicted in Figure 3D). Furthermore, the $M L H 1 / M S H 2$ phenotype was assessed as mentioned above ( $M L H 1$ : median $=850$ counts; $M S H 2$ : median $=612$ counts) and reached significance with respect
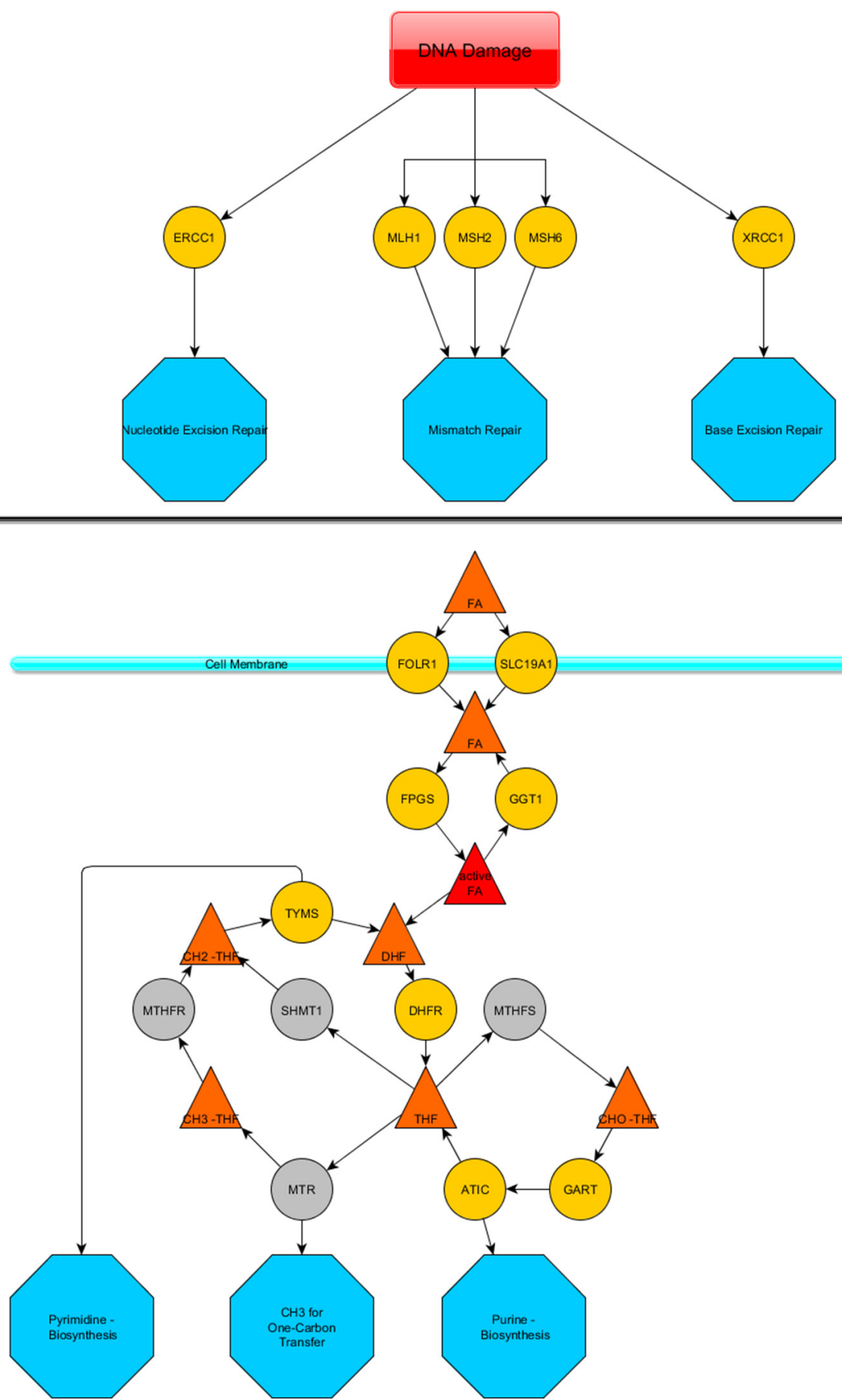

Figure 1: Sketch of the investigated DNA repair members and folic acid pathway. The upper line A. depicts the DNA damage response members that were investigated and their mode of action (blue octahedrons). The lower line B. presents a summary of the folic acid metabolism pathway. Yellow spheres represent mRNAs that were assessed via the nCounter technology. Grey spheres were not assessed. A cell membrane is pictured by a pale blue line associated with two spheres, which represent transmembrane proteins. Triangles depict conjugates of folic acid that is substrate/product of the mentioned enzymes. Blue octahedrons represent the final deployment of the modified folic acids. 
to tumor type $(p=0.0014)$ as shown in Figure $4 \mathrm{C}$. The M1m2- and M1M2-phenotype correlated with carcinoids ( $60 \%$ of $\mathrm{TC}$ and $>90 \%$ of AC), whereas carcinomas showed mostly reduced MSH1 expression (m1m2 or $\mathrm{m} 1 \mathrm{M} 2$ in $>80 \%$ of LCNEC and $>65 \%$ of SCLC). ERCC1 (OS: $\mathrm{p}=0.0082, \mathrm{HR}=1, \mathrm{PFS}: \mathrm{p}=0.0026, \mathrm{HR}=1$, data not shown) associated with survival. These and additional results are summarized in Table 1.

\section{DISCUSSION}

The mRNA level of eight genes involved in the folic acid metabolism and five genes of DNA damage repair were investigated in 60 NELC to identify subgroups that could benefit from cisplatin/pemetrexed therapy or show mechanisms of resistance against these regimens. One reason for the lack of comprehensive studies in NELC is the rather low frequency of TC and $\mathrm{AC}$ in the general lung cancer patient population. Due to the high number of lung cancer cases diagnosed at our tertiary cancer centre, a sufficient number of pulmonary $\mathrm{TC}$ and $\mathrm{AC}$ cases were available for our study.

Folate receptor 1 (the protein of the FOLR1 gene) is usually absent in SCLC and infrequently expressed in LCNEC $[44,45]$, in accordance with our results. Overall, low FOLR1 expression was identified as marker for more aggressive NELC and associated with shorter OS and PFS. Although survival data for the investigated collective was limited to 35 patients for overall (OS) and 11 patients for progression-free survival (PFS) (10 and 8 events per group, respectively), we considered the results to be of interest due to their consistency to the above mentioned results.

Our group has recently reported the predictive value of FOLR1 expression in NSCLC patients receiving pemetrexed-based chemotherapy [46, 47], indicating FOLR1 as potent biomarker in lung cancer.

We observed a significantly different TYMS gene expression between AC, TC, LCNEC, and SCLC with significantly higher expression especially in SCLC
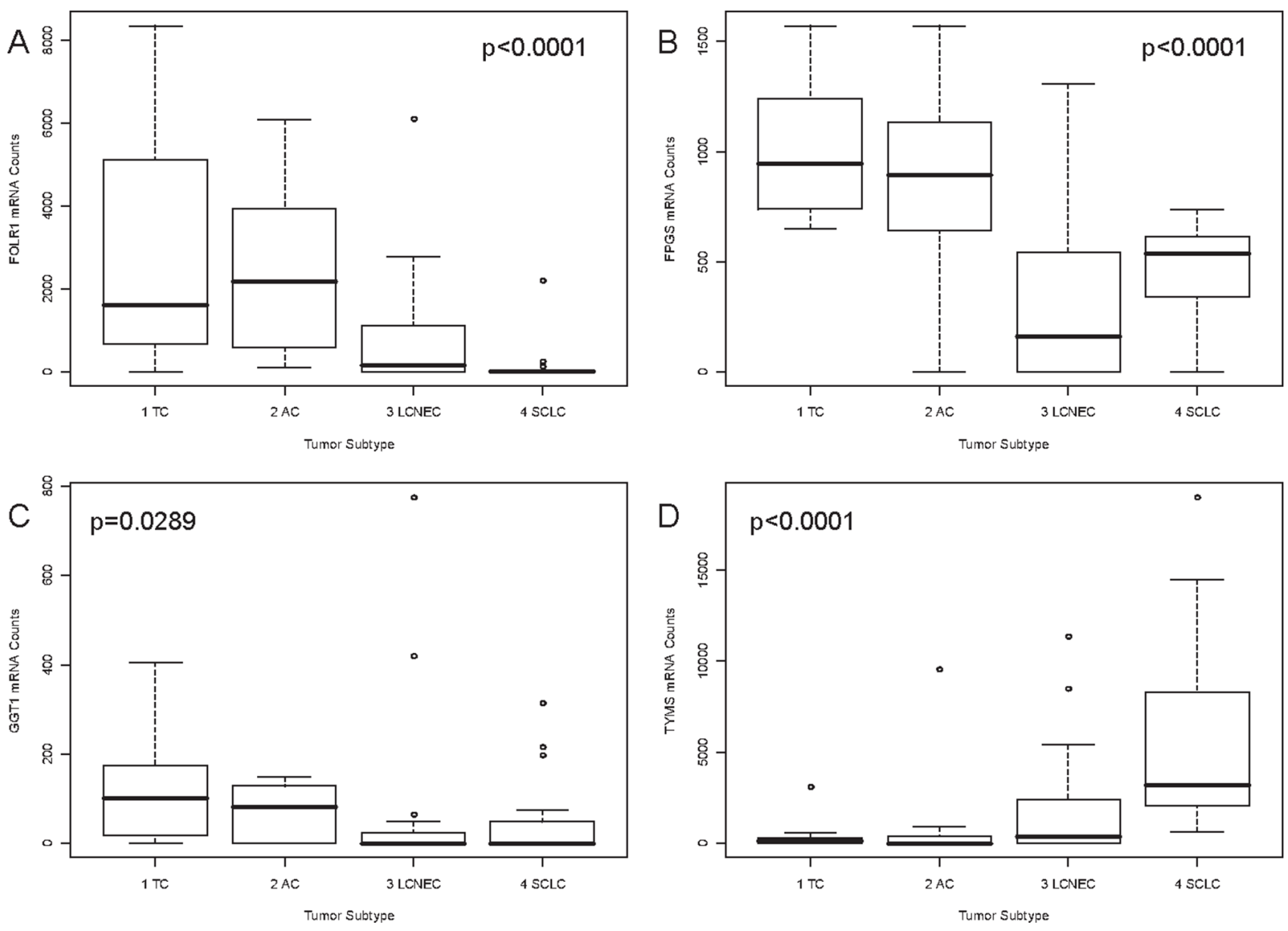

Figure 2: Correlation of FOLR1, FPGS, GGT1 and TYMS mRNA expression and tumor subtype. Associations between the tumor subtype and gene expression of A. FOLR1, B. FPGS, (upper line), C. GGT1 and D. TYMS (lower line) are pictured as boxplots. On the $\mathrm{x}$-axis the four investigated tumor subtypes are depicted. The y-axis shows the mRNA counts measured by the nCounter technology. The p-value is based on a Kruskal-Wallis rank sum test and is rounded to the fourth decimal place. FOLR1 and GGT1 expression decreased with increasing malignancy from TC to SCLC. The opposite was found for TYMS. FPGS showed higher expression in carcinoids than in carcinomas. 
Table 1: Summary of the statistical tests performed and obtained significances

Statistical Test

Tumor Type
FOLR1
FPGS
GGT1
TYMS
FOLR1/TYMS Ratio
FOLR1/SLC19A1 Ratio
FPGS/TYMS Ratio
FPGS/GGT1 Ratio
ERCC1
MLH1
XRCC1
MSH6
MLH1/MSH2 Ratio

FOLR1/TYMS Phenotype

FGPS/TYMS Phenotype

MLH1/MSH2 Phenotype

Pearson's Chi-squared test

$$
\begin{aligned}
& p<0.0001 \\
& p<0.0001 \\
& p=0.0014
\end{aligned}
$$

\section{Chi-square}

27.16

29.24

9.03

23.69

36.44

24.94

32.77

14.69

16.61

10.75

12.29

16.34

\section{Grade of Differentiation}

FOLR1

Spearman's rank correlation rho

X-squared

47.34

47.32

27.10

FPGS

$\mathrm{p}<0.0001$

rho

TYMS

$\mathrm{p}<0.0001$

$-0.6421$

GGT1

$\mathrm{p}<0.0001$

$-0.6501$

0.6329

ERCC1

$\mathrm{p}=0.0366$

$-0.2825$

MLH1

$\mathrm{p}<0.007$

$-0.3599$

MSH6

$\mathrm{p}=0.0046$

$-0.3766$

$\mathrm{p}=0.0210$

0.3105

Tumor Stage

FOLR1

ERCC1

MLH1

$X R C C 1$
Spearman's rank correlation rho

$$
\begin{aligned}
& p=0.0049 \\
& p=0.0147 \\
& p=0.0214 \\
& p=0.0226
\end{aligned}
$$

rho

$-0.4076$

$-0.3575$

$-0.3383$

$-0.3357$

(Continued) 
Statistical Test

\begin{tabular}{|c|c|c|}
\hline Spread to Lymph Nodes (N-Stage) & Spearman's rank correlation rho & rho \\
\hline FOLR1 & $\mathrm{p}=0.0001$ & -0.5192 \\
\hline$F P G S$ & $\mathrm{p}=0.0038$ & -0.4021 \\
\hline MLH1 & $\mathrm{p}=0.0111$ & -0.3562 \\
\hline Gender & $\begin{array}{c}\text { Exact Wilcoxon Mann-Whitney } \\
\text { Rank Sum Test }\end{array}$ & Z-value \\
\hline FOLR1 & $\mathrm{p}=0.0037$ & 2.87 \\
\hline$F P G S$ & $\mathrm{p}=0.0489$ & 1.97 \\
\hline ERCC1 & $\mathrm{p}=0.0408$ & 2.04 \\
\hline MLH1 & $\mathrm{p}=0.0308$ & 2.15 \\
\hline$X R C C 1$ & $\mathrm{p}=0.0246$ & 2.24 \\
\hline Overall Survival (OS) & Likelihood ratio test & Hazard Ratio \\
\hline \multicolumn{3}{|l|}{ Data for 35 patients ( 10 events) } \\
\hline FOLR1 & $\mathrm{p}=0.0014$ & 1.00 \\
\hline$F P G S$ & $\mathrm{p}<0.0004$ & 1.00 \\
\hline TYMS & $\mathrm{p}=0.0200$ & 0.99 \\
\hline$E R C C 1$ & $\mathrm{p}=0.0082$ & 1.00 \\
\hline MLH1 & $\mathrm{p}<0.0040$ & 1.00 \\
\hline$X R C C 1$ & $\mathrm{p}=0.0263$ & 1.00 \\
\hline FOLR1/TYMS Ratio & $\mathrm{p}<0.0040$ & 1.03 \\
\hline FOLR1/SLC19A1 Ratio & $\mathrm{p}=0.0017$ & 1.05 \\
\hline FPGS/TYMS Ratio & $\mathrm{p}<0.0001$ & 2.54 \\
\hline Progression-Free Survival (PFS) & Score (logrank) test & Hazard Ratio \\
\hline \multicolumn{3}{|l|}{ Data for 11 patients ( 8 events) } \\
\hline FOLR1 & $\mathrm{p}=0.0049$ & 0.99 \\
\hline ERCC1 & $\mathrm{p}=0.0026$ & 0.99 \\
\hline FOLR1/SLC19A1 Ratio & $\mathrm{p}=0.0223$ & 0.69 \\
\hline FOLR1/TYMS Ratio & $\mathrm{p}=0.0200$ & 0.26 \\
\hline FPGS/TYMS Ratio & $\mathrm{p}=0.0225$ & $<0.01$ \\
\hline
\end{tabular}

and particularly LCNEC. Similar results were found in retrospective studies using quantitative real-time PCR and immunohistochemistry [13,48]. Pemetrexed is a multitargeted antifolate that acts against TYMS, DHFR, GART and ATIC and is approved for the treatment of metastatic and unresectable non-squamous NSCLC [49]. Elevated expression of TYMS is believed to be one reason for the low efficacy of pemetrexed in SCLC [50]; similarly, squamous cell carcinomas of the lung express higher amounts of TYMS [51], which show poor response rates to pemetrexed-based therapies [49, 52]. Putatively, low levels of FPGS might be predictive for the efficacy of pemetrexed [21, 49].

In addition to the single marker assessment, which already revealed FOLR 1 and $F P G S$ as marker for aggressiveness and survival, the phenotypic sorting gave 
additional information and allowed for more detailed risk stratification of the investigated NELC. Phenotyping with respect to the folic acid metabolism revealed that SCLC show resistance to a pemetrexed therapy, because of the fT phenotype (low FOLR1 and FPGS, high TYMS). A large randomized phase III clinical trial (GALES; Global Analysis of pemetrexed in SCLC Extensive Stage) had to be aborted due to futility of pemetrexed plus carboplatin regimen compared to the standard etoposide plus carboplatin approach $[53,54]$, which can be explained by the supposed folic acid metabolism phenotype.

In contrast, carcinoids present predominantly with the Ft-phenotype indicating high FOLR1 and FPGS, but low TYMS gene expression levels. Especially, FOLR1 overexpression seems to be a tumor marker in a tissuedependant manner and has gained interest for targeted therapies via antibodies (e.g. farletuzumab) or new folic acid-drug conjugates (e.g. vintafolide) for selective inhibition, which were tested in clinical trails [55]. Hence, the Ft-phenotype found in TC/AC provides the rationale for the administration of pemetrexed for the treatment of unresectable or metastatic TC and AC, which commonly occur at a very low frequency (1 TC and $2 \mathrm{AC}$ in our study collective). Discussions about the efficacy of cisplatin/etoposide in this setting are ongoing [56] and no standard-of-care for chemotherapy exists. Three of the investigated carcinoids showed spread to regional lymph nodes indicating an aggressive subtype of a rather low-grade tumor. The phenotypic sorting with respect to folic acid metabolism revealed that two of them showed FOLR1 expression above the median expression (Ftphenotype) and also the third one showed a misbalance towards FOLR1 (FT-phenotype, with only $<3 \%$ above the median expression level of TYMS) indicating a potential benefit of an anti-folate therapy e.g. by pemetrexed or a new targeted therapy concept (vintafolide, farletuzumab) [55]. Of note, AC, TC and LCNEC belong to NSCLC [5], although of their neuroendocrine differentiation, and pemetrexed is approved for non-squamous NSCLC [49], making pemetrexed a reasonable therapy option.

With respect to the DNA-repair members, the lowest $M L H 1$ expression was found in LCNEC. A comparison of MLH1 expression between pulmonary adenocarcinomas, squamous cell carcinomas and LCNEC was reported showing normal $M L H 1$ expression (compared to normal bronchial mucosa) in 13 out of 18 LCNEC specimens and reduced expression in the remaining 5 specimens [57]. Reduction of MLH1 expression was reported to be a driver of platin resistance $[58,59]$ indicating that highgrade NELC are more prone to platin resistance than carcinoids, according to our results. Elevated expression of MSH2 was identified to contribute to such resistance mechanism [59]. The phenotypic sorting with respect to DNA repair revealed the negative prognostic $\mathrm{m} 1 \mathrm{~m} 2$ - and
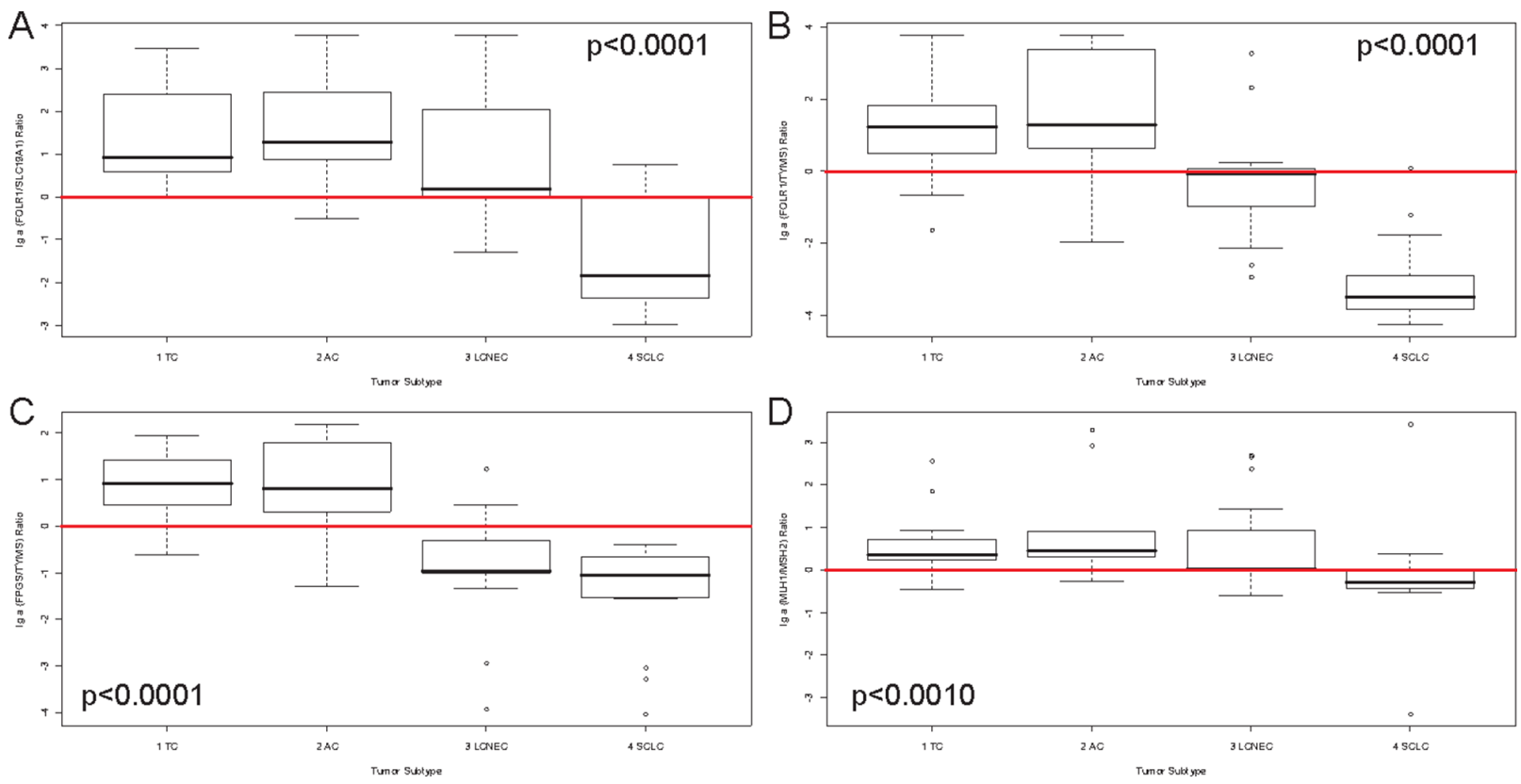

Figure 3: Ratios of members of folic acid metabolism and DNA repair discriminate different subtypes of pulmonary neuroendocrine tumors. The natural logarithmical scaled ratios for A. FOLR1/SLC19A1, B. FOLR1/TYMS, C. FPGS/TYMS and D. $M L H 1 / M S H 2$ are shown (y-axis) in correlation to the four investigated tumor subtypes (x-axis). The p-value is based on a Kruskal-Wallis rank sum test and is rounded to the fourth decimal place. A red line depicts the X-axis at the zero-point. The ratio depicted in A. differentiate SCLC from the other entities, indicating that SCLC use SLC19A1 as predominant receptor for uptake of folic acids. The ratios in B. and C. identify higher FOLRI and FPGS, but lower TYMS expression in carcinoids. In carcinomas, higher TYMS expression is found, whereas FOLRI and FPGS are considerably reduced. 
m1M2-phenotype to be associated with high-grade tumors indicating overall reduced $\mathrm{MLH} 1$ expression in high-grade NELC.

The NanoString nCounter system is a reproducible, sensitive and specific method that can detect even low abundance mRNAs that are below the detection limit of microarrays [35]. Additionally, the method is able to allow analysis of FFPE tissue yielding similar results as using fresh-frozen tissue for RNA investigations [60]. Due to the advanced stage at diagnosis, usually biopsies were collected from LCNEC and SCLC patients yielding rather small specimens and a huge part of these specimens was used for RNA extraction. We decided not to perform RT-PCR, because the NanoString nCounter system has already been validated in several publications [35, 36, 39, $41,60]$. A weakness of our current work is the lack of immunohistochemical investigations, which use antibodies specifically directed against functionally active enzymes. Discussions about their specificity and particularly about their ability to detect functionally active enzymes are ongoing [61]. Besides, validation of the nCounter technology by other techniques (e.g. qPCR, IHC, blotting etc.) may not be important as NanoString has launched an FDA- and CE-IVD-approved mRNA expression test (Prosigna) for the investigation of the PAM50-gene signature in FFPE-derived samples from breast cancer patients [62].

To summarize, gene expression of enzymes involved in folic acid metabolism as well as repair of DNA damage showed strong associations with the tumor entity in neuroendocrine tumors of the lung. Associations between the differentiation of these tumors, lymph node invasion and prognostic or predictive biomarkers could be identified. The supposed multi-marker assessment (phenotypic sorting) and system biological analysis can enhance risk stratification and provide additional guidance for therapy identification, also beyond lung cancer of the neuroendocrine subtype.
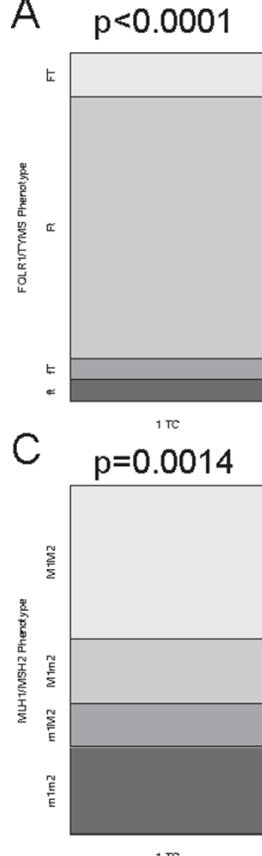

$1 \mathrm{TC}$
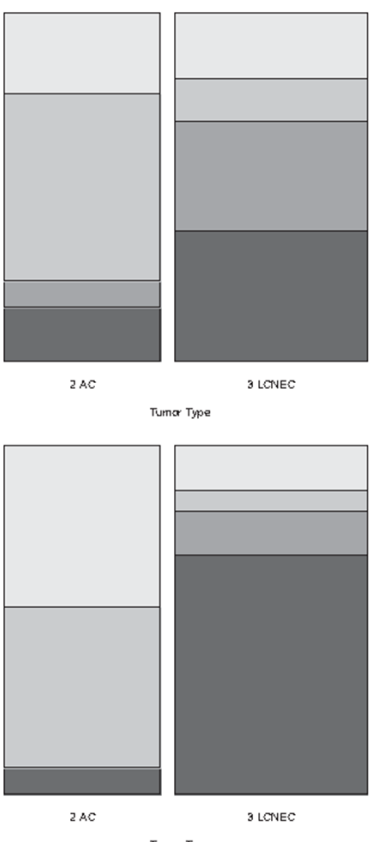

Tuma Trpe

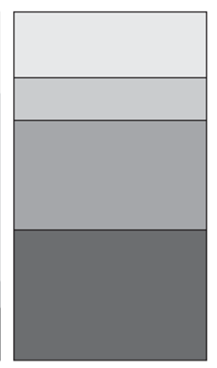

3 LONEC

(1)
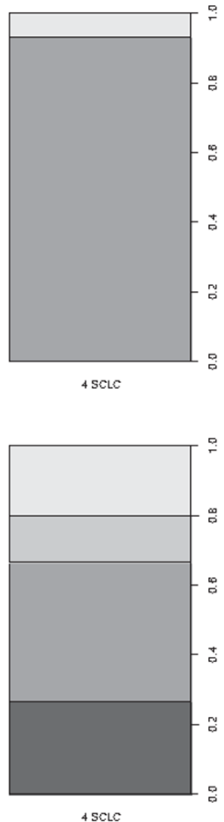

B $\quad p<0.0001$
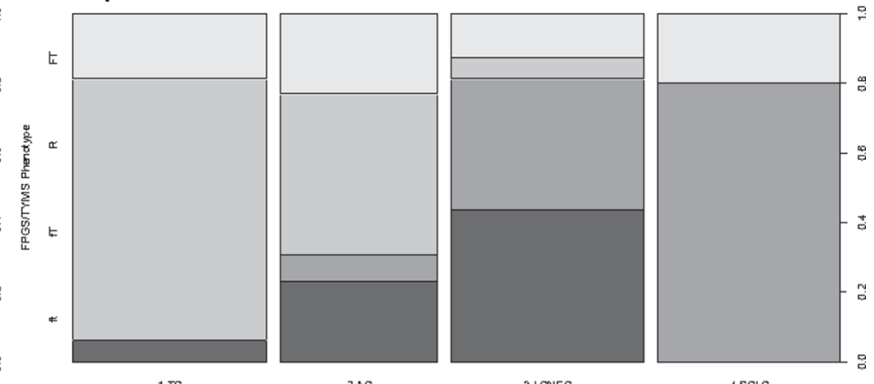
Tumor Type

Figure 4: Phenotypic sorting reveals differential expression patterns between carcinoids and carcinomas. The phenotypic distribution for A. FOLR1/TYMS, B. FPGS/TYMS and C. MLH1/MSH2 is shown for each tumor entity. Phenotypic sorting was performed by classifying expression below the median with a lowercase letter ( $\mathrm{f}, \mathrm{t}, \mathrm{m} 1, \mathrm{~m} 2$ ) and expression above the median with a capital letter (F, T, M1, M2): (FOLR1 (median=313 counts), FPGS (median=665 counts), TYMS (median=341 counts), MLH1 (median=850 counts), MSH2 (median=612 counts)). A. and B. show the folic acid phenotypes, whereas C. depicts the DNA repair phenotype. On the x-axis the four investigated tumor types are displayed. The y-axis depicts the percentaged distribution of each phenotype. The p-value is based on a Pearson's Chi-squared test and is rounded to the fourth decimal place. Approximately $90 \%$ of all TC and more than $75 \%$ of AC belong to the Ft- or FT-phenotype indicating high expression of FOLRI and FPGS, but low TYMS predestining them for a pemetrexed treatment. LCNEC present in equal shares ft- and fT-phenotypes making them resistant against pemetrexed. In $>95 \%$ of SCLC the fT-phenotype was present revealing why pemetrexed therapy is no option for this entity. With respect to DNA repair, LCNEC and SCLC present with the m1m2- and m1M2-phenotype in $>65 \%$ of all cases, which is linked to platin resistance. 


\section{MATERIALS AND METHODS}

\section{Study design}

For this biomarker exploratory study, sixty different formalin-fixed paraffin-embedded (FFPE) tumor specimens representative for each tumor entity (16 TC, 13 AC, 16 LCNEC, and 15 SCLC) were used for mRNA expression analysis. The initial diagnosis was made according to the WHO Classification Of Tumors [5], based on immunohistochemistry and confirmed by two experienced pathologists (JWO, THA). Only tumor specimens with a minimum of infiltration by lymphocytes or stromal cells and which were received from patients before any chemo- or radiotherapy were considered. The study included only patients with pulmonary neuroendocrine tumors, who were treated at the West German Cancer Centre between 2005 and 2011. Clinicopathological data included age, gender, histology, stages (Supplementary Table 1). Tumor staging was based on the tumor, node, and metastasis (TNM) staging system $\left(7^{\text {th }}\right.$ edition) as proposed by the International Association for the Study of Lung Cancer (IASLC) [40]. Progression-free survival (PFS) was calculated from the date of diagnosis until progression or loss to follow-up during any treatment. Overall survival (OS) was defined as the time between diagnosis until the date of death, or the date of last follow-up. Patients were censored at the last follow-up if still alive or lost to follow-up. Surveillance of PFS/OS for this study was stopped on August 31, 2014. The retrospective study was approved by the Ethics Committee of the Medical Faculty of the University Duisburg-Essen (identifier: 13-5382-BO). The investigation conforms to the principles outlined in the declaration of Helsinki.

\section{RNA extraction and RNA integrity assessment}

According to the manufacturer's recommendations, three to five FFPE sections with a thickness of $4 \mu \mathrm{m}$ per slide were deparaffinised with xylene prior to RNA extraction using the RNeasy FFPE kit (Qiagen, Venlo, Netherlands). RNA concentration was measured using a Nanodrop 1000 instrument (Thermo Fisher Scientific, WA, USA). RNA integrity was assessed using an Agilent 2100 Bioanalyzer (Agilent Technologies, CA, USA) at the NanoString nCounter Core Facility at the University of Heidelberg (Heidelberg, Germany). Smear analysis was performed
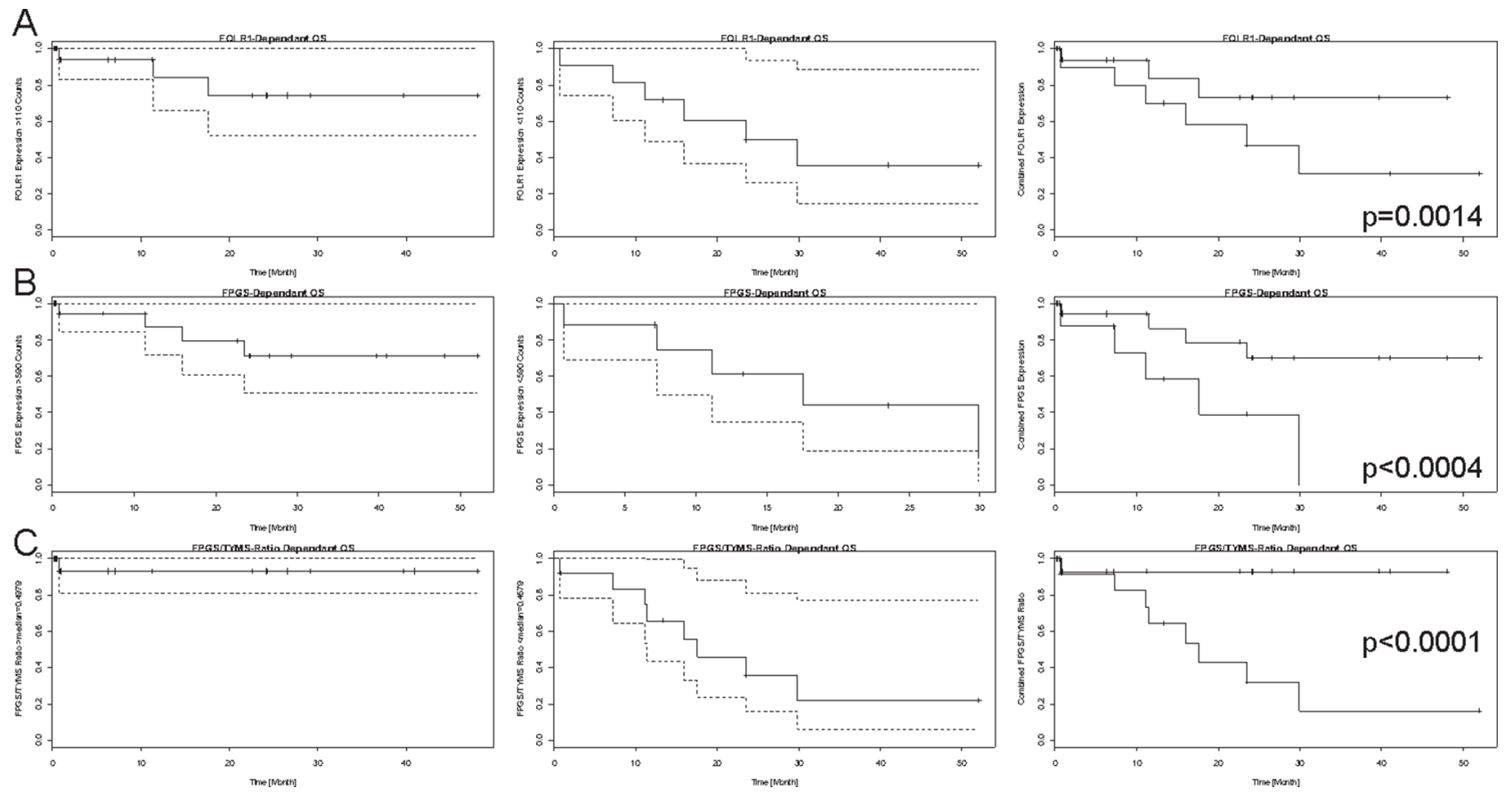

Figure 5: Kaplan-Meier curves for mRNA-expression dependant overall survival. Each line presents the single-fractional and combined Kaplan-Meier curves for A. FOLR1, B. FPGS and C. FPGS/TYMS ratio. The single-fractional curves on the left side display the expression-dependant survival above the chosen threshold (FOLRl=110 mRNA counts, FPGS=590 mRNA counts, and FPGS/TYMS ratio $=$ median $=0.4979$, empirically determined), whereas the single-fractional curves in the middle depict the survival curve for expression above the mentioned expression. Both curves contain the $95 \%$ confidence interval, which is pictured by the dashed lines. The combined survival curve is shown on the right side and contains the p-value, which was obtained by using the COXPH-model and is rounded to the fourth decimal place. The $\mathrm{x}$-axis is a time line and the $\mathrm{y}$-axis displays the number of events in a percentaged scale. Higher expression of FOLRI and FPGS correlated with prolonged survival and a higher FPGS expression than TYMS expression was identified as further positive prognostic marker. 
using the Agilent 2100 expert software to determine the proportion of $\mathrm{RNA} \geq 300 \mathrm{nt}$ within a given sample.

\section{NanoString CodeSet design and expression quantification}

Important genes of the folic acid metabolism (eight genes: ATIC, DHFR, FOLR1, FPGS, GART, GGT1, SLC19A1, TYMS) and DNA damage repair (five genes: ERCC1, MLH1, MSH2, MSH6, XRCC1) were included in the CodeSet. The complete CodeSet was designed to contain a total of 91 genes with different signature genes for each tumor entity and some results have been published previously $[36,39,41]$. Three potential reference genes ( $A C T B, G A P D H$, and HPRTI) were also included in the CodeSet for biological normalization purposes [38, 42]. Probe sets for each gene in the CodeSet were designed and synthesized at NanoString Technologies (Seattle, WA, USA). Total RNA (100 ng) including mRNA and miRNA was measured at the NanoString nCounter Core Facility at the University of Heidelberg, Germany.

\section{NanoString data processing and statistical analysis}

Raw NanoString counts for each gene were subjected to a technical normalization taking positive and negative probes into account. A background correction was carried out by subtracting average negative-control counts plus two-times standard deviation from each target counts. After this procedure a biological normalization using reference genes was performed by choosing appropriate reference genes based on the geNorm algorithm [43]. All statistical analyses were calculated with the R statistical programming environment (v3.1.1.). For dichotomous factors such as gender and expression level the Wilcoxon Mann-Whitney rank sum test was applied. For variables with more than two categories the Kruskal-Wallis test was done. Associations between gene expression of tested genes and associations between gene expression and TNM-criteria were analyzed by Spearman's rank correlation test. Two-dimensional contingency tables were analyzed using the Pearson's Chisquared test.

Kaplan-Meier analysis was done for the assessment of associations between gene expression and survival data. Significant survival differences between groups were verified by COXPH-model using a confidence interval of 95\% for the Wald-test, likelihood-ratio test and Score (logrank) test. The level of statistical significance was defined as $\mathrm{p} \leq 0.05$.

\section{ACKNOWLEDGMENTS}

We thank the nCounter Core Facility Heidelberg for providing the nCounter system and related services.
We thank the yWorks GmbH for providing the yEd Graph Editor that was used to produce Figure 1 (http:// www.yworks.com/yed).

\section{CONFLICTS OF INTEREST}

All authors state that they have no conflicts of interest to declare.

\section{Abbreviations}

AC, atypical carcinoids; ALK, anaplastic lymphoma receptor tyrosine kinase; CI, confidence interval; DHFR, dihydrofolate reductase; EGFR, epidermal growth factor receptor; ERCC1, excision repair cross-complementing group 1; FOLR1, folate receptor 1; FFPE, formalinfixed, paraffin-embedded; FPGS, folylpolyglutamate synthase; GART, phosphoribosylglycinamide formyltransferase, phosphoribosylglycinamide synthetase, phosphoribosylaminoimidazole synthetase or glycinamide ribonucleotide formyltransferases; GGT1, gammaglutamyltransferase 1; HR, hazard ratio; LCNEC, largecell neuroendocrine cancer; MLH1, mutL homolog 1; MMR, mismatch repair; MSH2, mutS homolog 2; nt, nucleotides; NELC, neuroendocrine lung cancer; NER, nucleotide excision repair; NSCLC, non-small cell lung cancer; OS, overall survival; PFS, progressionfree survival; SLC19A1, solute carrier family 19 (folate transporter), member 1; SLC46A1, solute carrier family 46 (folate transporter), member 1; SCLC, small cell lung cancer; TYMS, thymidylate synthetase; TC, typical carcinoids; WHO, world health organization; XRCC1, $\mathrm{x}$-ray repair complementing defective repair in Chinese hamster cells 1 .

\section{Editorial note}

This paper has been accepted based in part on peerreview conducted by another journal and the authors' response and revisions as well as expedited peer-review in Oncotarget.

\section{REFERENCES}

1. Torre LA, Bray F, Siegel RL, Ferlay J, Lortet-Tieulent J, Jemal A. Global cancer statistics, 2012. CA: a cancer journal for clinicians. 2015; 65:87-108.

2. Rekhtman N. Neuroendocrine tumors of the lung: an update. Archives of pathology \& laboratory medicine. 2010; 134:1628-1638.

3. Asamura H, Kameya T, Matsuno Y, Noguchi M, Tada H, Ishikawa Y, Yokose T, Jiang SX, Inoue T, Nakagawa K, 
Tajima K, Nagai K. Neuroendocrine neoplasms of the lung: a prognostic spectrum. Journal of clinical oncology. 2006; 24:70-76.

4. Travis WD. Lung tumours with neuroendocrine differentiation. European journal of cancer. 2009; 45:251-266.

5. Travis WD, World Health Organization., International Agency for Research on Cancer., International Association for the Study of Lung Cancer and International Academy of Pathology. (2004). Pathology and genetics of tumours of the lung, pleura, thymus and heart. (Lyon Oxford: IARC Press Oxford University Press).

6. Takei H, Asamura H, Maeshima A, Suzuki K, Kondo H, Niki T, Yamada T, Tsuchiya R, Matsuno Y. Large cell neuroendocrine carcinoma of the lung: a clinicopathologic study of eighty-seven cases. The Journal of thoracic and cardiovascular surgery. 2002; 124:285-292.

7. Swarts DR, Ramaekers FC, Speel EJ. Molecular and cellular biology of neuroendocrine lung tumors: evidence for separate biological entities. Biochimica et biophysica acta. $2012 ; 1826: 255-271$.

8. Travis WD, Gal AA, Colby TV, Klimstra DS, Falk R, Koss MN. Reproducibility of neuroendocrine lung tumor classification. Human pathology. 1998; 29:272-279.

9. Travis WD, Rush W, Flieder DB, Falk R, Fleming MV, Gal AA, Koss MN. Survival analysis of 200 pulmonary neuroendocrine tumors with clarification of criteria for atypical carcinoid and its separation from typical carcinoid. The American journal of surgical pathology. 1998; 22:934-944.

10. Peters S, Adjei AA, Gridelli C, Reck M, Kerr K, Felip E, Group EGW. Metastatic non-small-cell lung cancer (NSCLC): ESMO Clinical Practice Guidelines for diagnosis, treatment and follow-up. Annals of oncology. 2012; 23:vii56-64.

11. Scagliotti GV, Parikh P, von Pawel J, Biesma B, Vansteenkiste J, Manegold C, Serwatowski P, Gatzemeier U, Digumarti R, Zukin M, Lee JS, Mellemgaard A, Park K, Patil S, Rolski J, Goksel T, et al. Phase III study comparing cisplatin plus gemcitabine with cisplatin plus pemetrexed in chemotherapy-naive patients with advanced-stage nonsmall-cell lung cancer. Journal of clinical oncology. 2008; 26:3543-3551.

12. Gronberg $\mathrm{BH}$, Bremnes RM, Flotten $\mathrm{O}$, Amundsen $\mathrm{T}$, Brunsvig PF, Hjelde HH, Kaasa S, von Plessen C, Stornes F, Tollali T, Wammer F, Aasebo U, Sundstrom S. Phase III study by the Norwegian lung cancer study group: pemetrexed plus carboplatin compared with gemcitabine plus carboplatin as first-line chemotherapy in advanced non-small-cell lung cancer. Journal of clinical oncology. 2009; 27:3217-3224.

13. Monica V, Scagliotti GV, Ceppi P, Righi L, Cambieri A, Lo Iacono M, Saviozzi S, Volante M, Novello S, Papotti M.
Differential Thymidylate Synthase Expression in Different Variants of Large-Cell Carcinoma of the Lung. Clinical cancer research. 2009; 15:7547-7552.

14. Belani CP, Wu YL, Chen YM, Kim JH, Yang SH, Zhang L, Peterson P, Orlando M. Efficacy and safety of pemetrexed maintenance therapy versus best supportive care in patients from East Asia with advanced, nonsquamous nonsmall cell lung cancer: an exploratory subgroup analysis of a global, randomized, phase 3 clinical trial. Journal of thoracic oncology. 2012; 7:567-573.

15. Ciuleanu T, Brodowicz T, Zielinski C, Kim JH, Krzakowski M, Laack E, Wu YL, Bover I, Begbie S, Tzekova V, Cucevic B, Pereira JR, Yang SH, Madhavan J, Sugarman $\mathrm{KP}$, Peterson P, et al. Maintenance pemetrexed plus best supportive care versus placebo plus best supportive care for non-small-cell lung cancer: a randomised, double-blind, phase 3 study. Lancet. 2009; 374:1432-1440.

16. Bearz A, Garassino I, Cavina R, Favaretto A, Boccalon M, Talamini R, Berretta M, Spazzapan S, Simonelli C, Santoro A, Tirelli U. Pemetrexed single agent in previously treated non-small cell lung cancer: a multi-institutional observational study. Lung cancer. 2008; 60:240-245.

17. Assaraf YG. Molecular basis of antifolate resistance. Cancer metastasis reviews. 2007; 26:153-181.

18. Adjei AA. Pharmacology and mechanism of action of pemetrexed. Clinical lung cancer. 2004; 5:S51-55.

19. Liani E, Rothem L, Bunni MA, Smith CA, Jansen G, Assaraf YG. Loss of folylpoly-gamma-glutamate synthetase activity is a dominant mechanism of resistance to polyglutamylation-dependent novel antifolates in multiple human leukemia sublines. International journal of cancer. 2003; 103:587-599.

20. Adjei AA. Pemetrexed (ALIMTA), a novel multitargeted antineoplastic agent. Clinical cancer research : an official journal of the American Association for Cancer Research. 2004; 10:4276s-4280s.

21. Christoph DC, Asuncion BR, Mascaux C, Tran C, Lu X, Wynes MW, Gauler TC, Wohlschlaeger J, Theegarten D, Neumann V, Hepp R, Welter S, Stamatis G, Tannapfel A, Schuler M, Eberhardt WE, et al. Folylpoly-glutamate synthetase expression is associated with tumor response and outcome from pemetrexed-based chemotherapy in malignant pleural mesothelioma. Journal of thoracic oncology. 2012; 7:1440-1448.

22. Camps C, Sarries C, Roig B, Sanchez JJ, Queralt C, Sancho E, Martinez N, Taron M, Rosell R. Assessment of nucleotide excision repair XPD polymorphisms in the peripheral blood of gemcitabine/cisplatin-treated advanced non-small-cell lung cancer patients. Clinical lung cancer. 2003; 4:237-241.

23. Rosell R, Taron M, Barnadas A, Scagliotti G, Sarries C, Roig B. Nucleotide excision repair pathways involved in 
Cisplatin resistance in non-small-cell lung cancer. Cancer control. 2003; 10:297-305.

24. Hubner RA, Riley RD, Billingham LJ, Popat S. Excision repair cross-complementation group 1 (ERCC1) status and lung cancer outcomes: a meta-analysis of published studies and recommendations. PloS one. 2011; 6:e25164.

25. Kerr KM. Personalized medicine for lung cancer: new challenges for pathology. Histopathology. 2012; 60:531-546.

26. Kamal NS, Soria JC, Mendiboure J, Planchard D, Olaussen KA, Rousseau V, Popper H, Pirker R, Bertrand P, Dunant A, Le Chevalier T, Filipits M, Fouret P and International Adjuvant Lung Trial-Bio i. MutS homologue 2 and the long-term benefit of adjuvant chemotherapy in lung cancer. Clinical cancer research. 2010; 16:1206-1215.

27. Cobo M, Isla D, Massuti B, Montes A, Sanchez JM, Provencio M, Vinolas N, Paz-Ares L, Lopez-Vivanco G, Munoz MA, Felip E, Alberola V, Camps C, Domine M, Sanchez JJ, Sanchez-Ronco M, et al. Customizing cisplatin based on quantitative excision repair cross-complementing 1 mRNA expression: a phase III trial in non-small-cell lung cancer. Journal of clinical oncology. 2007; 25:2747-2754.

28. Kang CH, Jang BG, Kim DW, Chung DH, Kim YT, Jheon S, Sung SW, Kim JH. Differences in the expression profiles of excision repair crosscomplementation group 1, x-ray repair crosscomplementation group 1, and betaIII-tubulin between primary non-small cell lung cancer and metastatic lymph nodes and the significance in mid-term survival. Journal of thoracic oncology. 2009; 4:1307-1312.

29. Kang CH, Jang BG, Kim DW, Chung DH, Kim YT, Jheon S, Sung SW, Kim JH. The prognostic significance of ERCC1, BRCA1, XRCC1, and betaIII-tubulin expression in patients with non-small cell lung cancer treated by platinum- and taxane-based neoadjuvant chemotherapy and surgical resection. Lung cancer. 2010; 68:478-483.

30. Martin SA, Lord CJ, Ashworth A. DNA repair deficiency as a therapeutic target in cancer. Current opinion in genetics \& development. 2008; 18:80-86.

31. Martin SA, McCabe N, Mullarkey M, Cummins R, Burgess DJ, Nakabeppu Y, Oka S, Kay E, Lord CJ, Ashworth A. DNA polymerases as potential therapeutic targets for cancers deficient in the DNA mismatch repair proteins MSH2 or MLH1. Cancer cell. 2010; 17:235-248.

32. Ting S, Mairinger FD, Hager T, Welter S, Eberhardt WE, Wohlschlaeger J, Schmid KW, Christoph DC. ERCC1, MLH1, MSH2, MSH6, and betaIII-tubulin: resistance proteins associated with response and outcome to platinumbased chemotherapy in malignant pleural mesothelioma. Clinical lung cancer. 2013; 14:558-567 e553.

33. Lo YL, Hsiao CF, Jou YS, Chang GC, Tsai YH, Su WC, Chen KY, Chen YM, Huang MS, Hsieh WS, Chen CJ, Hsiung CA. Polymorphisms of MLH1 and MSH2 genes and the risk of lung cancer among never smokers. Lung cancer. $2011 ; 72: 280-286$.
34. Vageli D, Daniil Z, Dahabreh J, Karagianni E, Vamvakopoulou DN, Ioannou MG, Scarpinato K, Vamvakopoulos NC, Gourgoulianis KI, Koukoulis GK. Phenotypic mismatch repair hMSH2 and hMLH1 gene expression profiles in primary non-small cell lung carcinomas. Lung cancer. 2009; 64:282-288.

35. Geiss GK, Bumgarner RE, Birditt B, Dahl T, Dowidar N, Dunaway DL, Fell HP, Ferree S, George RD, Grogan T, James JJ, Maysuria M, Mitton JD, Oliveri P, Osborn JL, Peng T, et al. Direct multiplexed measurement of gene expression with color-coded probe pairs. Nature biotechnology. 2008; 26:317-325.

36. Walter RF, Werner R, Ting S, Vollbrecht C, Theegarten D, Christoph DC, Schmid KW, Wohlschlaeger J, Mairinger FD. Identification of deregulation of apoptosis and cell cycle in neuroendocrine tumors of the lung via NanoString nCounter expression analysis. Oncotarget. 2015. doi: 10.18632/oncotarget.3992.

37. Waggott D, Chu K, Yin S, Wouters BG, Liu FF, Boutros PC. NanoStringNorm: an extensible R package for the pre-processing of NanoString mRNA and miRNA data. Bioinformatics. 2012; 28:1546-1548.

38. Walter RF, Mairinger FD, Wohlschlaeger J, Worm K, Ting $\mathrm{S}$, Vollbrecht C, Schmid KW, Hager T. FFPE tissue as a feasible source for gene expression analysis-a comparison of three reference genes and one tumor marker. Pathology, research and practice. 2013; 209:784-789.

39. Walter RF, Mairinger FD, Werner R, Ting S, Vollbrecht C, Theegarten D, Christoph DC, Zarogoulidis K, Schmid KW, Zarogoulidis P, Wohlschlaeger J. SOX4, SOX11 and PAX6 mRNA expression was identified as a (prognostic) marker for the aggressiveness of neuroendocrine tumors of the lung by using next-generation expression analysis (NanoString). Future oncology. 2015; 11:1027-1036.

40. Detterbeck FC, Boffa DJ, Tanoue LT. The new lung cancer staging system. Chest. 2009; 136:260-271.

41. Mairinger FD, Walter RF, Werner R, Christoph DC, Ting S, Vollbrecht C, Zarogoulidis K, Huang H, Li Q, Schmid KW, Wohlschlaeger J, Zarogoulidis P. Activation of angiogenesis differs strongly between pulmonary carcinoids and neuroendocrine carinomas and is crucial for carcinoid tumourgenesis. Journal of Cancer. 2014; 5:465-471.

42. Mairinger FD, Walter RF, Theegarten $\mathrm{D}$, Hager $\mathrm{T}$, Vollbrecht C, Christoph DC, Worm K, Ting S, Werner R, Stamatis G, Mairinger T, Baba H, Zarogoulidis K, Huang H, Li Q, Tsakiridis K, et al. Gene Expression Analysis of the 26S Proteasome Subunit PSMB4 Reveals Significant Upregulation, Different Expression and Association with Proliferation in Human Pulmonary Neuroendocrine Tumours. Journal of Cancer. 2014; 5:646-654.

43. Vandesompele J, De Preter K, Pattyn F, Poppe B, Van Roy N, De Paepe A, Speleman F. Accurate normalization of real-time quantitative RT-PCR data by geometric averaging of multiple internal control genes. Genome biology. 2002; 3:RESEARCH0034. 
44. Franklin WA, Waintrub M, Edwards D, Christensen K, Prendegrast P, Woods J, Bunn PA, Kolhouse JF. New antilung-cancer antibody cluster 12 reacts with human folate receptors present on adenocarcinoma. International journal of cancer Supplement. 1994; 8:89-95.

45. O’Shannessy DJ, Yu G, Smale R, Fu YS, Singhal S, Thiel RP, Somers EB, Vachani A. Folate receptor alpha expression in lung cancer: diagnostic and prognostic significance. Oncotarget. 2012; 3:414-425. doi: 10.18632/ oncotarget.489.

46. Christoph DC, Asuncion BR, Hassan B, Tran C, Maltzman JD, O’Shannessy DJ, Wynes MW, Gauler TC, Wohlschlaeger J, Hoiczyk M, Schuler M, Eberhardt WE, Hirsch FR. Significance of folate receptor alpha and thymidylate synthase protein expression in patients with non-small-cell lung cancer treated with pemetrexed. Journal of thoracic oncology. 2013; 8:19-30.

47. Christoph DC, Reyna-Asuncion B, Hassan B, Tran C, Maltzman JD, O'Shannessy DJ, Gauler TC, Wohlschlaeger J, Schuler M, Eberhardt WE, Hirsch FR. Assessment of folate receptor-alpha and epidermal growth factor receptor expression in pemetrexed-treated non-small-cell lung cancer patients. Clinical lung cancer. 2014; 15:320-330 e321-323.

48. Nagasaki T, Tsuchiya T, Tagawa $T$, Honda S, Yamasaki N, Miyazaki T, Hidaka S, Hayashi T, Nagayasu T. Analysis of 5-fluorouracil-related enzymes in pulmonary neuroendocrine carcinoma: differences in biological properties compared to epithelial carcinoma. Clinical lung cancer. 2010; 11:412-422.

49. Ozasa H, Oguri T, Uemura T, Miyazaki M, Maeno K, Sato S, Ueda R. Significance of thymidylate synthase for resistance to pemetrexed in lung cancer. Cancer science. 2010; 101:161-166.

50. Joerger M, Omlin A, Cerny T, Fruh M. The role of pemetrexed in advanced non small-cell lung cancer: special focus on pharmacology and mechanism of action. Current drug targets. 2010; 11:37-47.

51. Ceppi P, Volante M, Saviozzi S, Rapa I, Novello S, Cambieri A, Lo Iacono M, Cappia S, Papotti M, Scagliotti GV. Squamous cell carcinoma of the lung compared with other histotypes shows higher messenger RNA and protein levels for thymidylate synthase. Cancer. 2006; 107:1589-1596.

52. Scagliotti G, Hanna N, Fossella F, Sugarman K, Blatter J, Peterson P, Simms L, Shepherd FA. The differential efficacy of pemetrexed according to NSCLC histology: a review of two Phase III studies. The oncologist. 2009; 14:253-263.

53. Smit EF, Socinski MA, Mullaney BP, Myrand SP, Scagliotti GV, Lorigan P, Reck M, Ciuleanu T, von Pawel J, Karaseva NA, Szczesna A, Ohannesian D, Powell E, Hozak RR, Hong $\mathrm{S}$, Guba SC, et al. Biomarker analysis in a phase III study of pemetrexed-carboplatin versus etoposide-carboplatin in chemonaive patients with extensive-stage small-cell lung cancer. Annals of oncology. 2012; 23:1723-1729.

54. Socinski MA, Smit EF, Lorigan P, Konduri K, Reck M, Szczesna A, Blakely J, Serwatowski P, Karaseva NA, Ciuleanu T, Jassem J, Dediu M, Hong S, Visseren-Grul C, Hanauske AR, Obasaju CK, et al. Phase III study of pemetrexed plus carboplatin compared with etoposide plus carboplatin in chemotherapy-naive patients with extensivestage small-cell lung cancer. Journal of clinical oncology. 2009; 27:4787-4792.

55. Necela BM, Crozier JA, Andorfer CA, Lewis-Tuffin L, Kachergus JM, Geiger XJ, Kalari KR, Serie DJ, Sun Z, Aspita AM, O’Shannessy DJ, Maltzman JD, McCullough AE, Pockaj BA, Cunliffe HE, Ballman KV, et al. Folate receptor-alpha (FOLR1) expression and function in triple negative tumors. PloS one. 2015; 10:e0122209.

56. Horsch D, Sayeg Y, Bonnet R, Kaemmerer D, Presselt N, Baum RP. [Expert dialogue: neuroendocrine tumours of the lungs and gastroenteropancreatic system]. Pneumologie. 2012; 66:44-48.

57. Cooper WA, Kohonen-Corish MR, Chan C, Kwun SY, McCaughan B, Kennedy C, Sutherland RL, Lee CS. Prognostic significance of DNA repair proteins MLH1, MSH2 and MGMT expression in non-small-cell lung cancer and precursor lesions. Histopathology. 2008; 52:613-622.

58. Aebi S, Kurdi-Haidar B, Gordon R, Cenni B, Zheng H, Fink D, Christen RD, Boland CR, Koi M, Fishel R, Howell $\mathrm{SB}$. Loss of DNA mismatch repair in acquired resistance to cisplatin. Cancer research. 1996; 56:3087-3090.

59. Fink D, Nebel S, Aebi S, Zheng H, Cenni B, Nehme A, Christen RD, Howell SB. The role of DNA mismatch repair in platinum drug resistance. Cancer research. 1996; 56:4881-4886.

60. Reis PP, Waldron L, Goswami RS, Xu W, Xuan Y, PerezOrdonez B, Gullane P, Irish J, Jurisica I, Kamel-Reid S. mRNA transcript quantification in archival samples using multiplexed, color-coded probes. BMC biotechnology. 2011; 11:46.

61. Friboulet L, Olaussen KA, Pignon JP, Shepherd FA, Tsao MS, Graziano S, Kratzke R, Douillard JY, Seymour L, Pirker R, Filipits M, Andre F, Solary E, Ponsonnailles F, Robin A, Stoclin A, et al. ERCC1 isoform expression and DNA repair in non-small-cell lung cancer. The New England journal of medicine. 2013; 368:1101-1110.

62. Nielsen T, Wallden B, Schaper C, Ferree S, Liu S, Gao D, Barry G, Dowidar N, Maysuria M, Storhoff J. Analytical validation of the PAM50-based Prosigna Breast Cancer Prognostic Gene Signature Assay and nCounter Analysis System using formalin-fixed paraffin-embedded breast tumor specimens. BMC cancer. 2014; 14:177. 